\title{
A construction of 4,4-spirocyclic $y$-lactams by tandem radical cyclization with carbon monoxide
}

\author{
Mitsuhiro Ueda ${ }^{1}$, Yoshitaka Uenoyama ${ }^{1}$, Nozomi Terasoma ${ }^{1}$, Shoko Doi ${ }^{1}$, \\ Shoji Kobayashi ${ }^{2}$, Ilhyong Ryu ${ }^{* 1}$ and John A. Murphy ${ }^{* 3}$
}

\section{Letter}

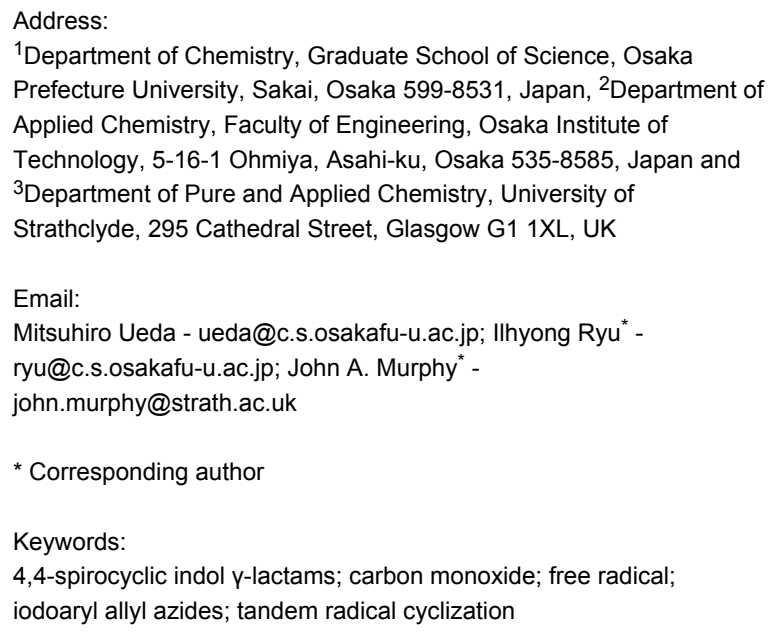

${ }^{1}$ Department of Chemistry, Graduate School of Science, Osaka Prefecture University, Sakai, Osaka 599-8531, Japan, ${ }^{2}$ Department of Applied Chemistry, Faculty of Engineering, Osaka Institute of Technology, 5-16-1 Ohmiya, Asahi-ku, Osaka 535-8585, Japan and ${ }^{3}$ Department of Pure and Applied Chemistry, University of Strathclyde, 295 Cathedral Street, Glasgow G1 1XL, UK

\section{Email:}

Mitsuhiro Ueda - ueda@c.s.osakafu-u.ac.jp; Ilhyong Ryu* ryu@c.s.osakafu-u.ac.jp; John A. Murphy* -

* Corresponding author

Keywords:

4,4-spirocyclic indol y-lactams; carbon monoxide; free radical; iodoaryl allyl azides; tandem radical cyclization

\begin{abstract}
A straightforward synthesis of 4,4-spirocyclic indol $\gamma$-lactams by tandem radical cyclization of iodoaryl allyl azides with CO was achieved. The reaction of iodoaryl allyl azides, TTMSS and AIBN under CO pressure $(80 \mathrm{~atm})$ in THF at $80{ }^{\circ} \mathrm{C}$ gave the desired 4,4-spirocyclic indoline, benzofuran, and oxindole $\gamma$-lactams in moderate to good yields.
\end{abstract}

\section{Introduction}

4,4-Spirocyclic oxindole $\gamma$-lactams containing a quaternary carbon center are key structures for the synthesis of biologically active natural products and the related analogues [1-4]. Therefore, the development of an efficient synthesis of this spiro structure is of continued interest for synthetic chemists. Recently, Comesse and Daïch reported the synthesis of 4,4spirocyclic oxindole $\gamma$-lactams by tandem spirocyclization via nucleophilic halide displacement and amide coupling [4]. Shaw and co-workers reported the synthesis of 4,4-spirocyclic oxindole $\gamma$-lactams by the cycloaddition of imines and succinic anhydrides [5]. Tandem radical cyclization can also provide a powerful tool for the construction of heterocycles [6-12]. One of us previously reported on the construction of spirocyclic pyrrolidinyl oxindoles by the tandem reaction of iodoaryl alkenyl azides under radical conditions (Scheme 1) [13,14]. Curran et al. reported the synthesis of spirocyclic pyrrolidinyl dihydroquinolinones by tandem radical cyclization $[15,16]$.

In this study we report a radical cyclization/annulation approach to 4.4 -spirocyclic $\gamma$-lactams in which CO was intro- 
<smiles>C=C(I)C(=O)Nc1ccc(OC)cc1I</smiles>

$\mathrm{Bn}$

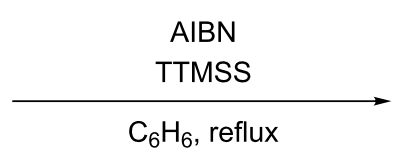

$\mathrm{C}_{6} \mathrm{H}_{6}$, reflux<smiles>COc1ccc2c(c1)C1(CCNC1)C(=O)N2Cc1ccccc1</smiles><smiles>C=C(CCN)C(=O)N(Cc1ccccc1)c1ccc(OC)cc1</smiles>

Scheme 1: A construction of spirocyclic pyrrolidinyl oxindole by tandem radical cyclization with azide [14].

duced as the lactam carbonyl moiety [17-23]. Our approach consists of a sequence of aryl radical cyclization, radical carbonylation [24-27], and spirocyclization of the resulting acyl radical onto an azide group, which can give 4,4-spirocyclic $\gamma$-lactams (Scheme 2).

\section{Results and Discussion}

For the first model reaction in our investigation of the development of a novel tandem radical cyclization/annulation strategy, we prepared $N$-(2-(azidomethyl)allyl)- $N$-(2-iodophenyl)-4methylbenzenesulfonamide (1a) according to the methods shown in Scheme 3. The reaction of $\mathbf{1 a}$ with $\mathrm{Bu}_{3} \mathrm{SnH}$ (2.0 equiv) and $\operatorname{AIBN}\left(2,2^{\prime}\right.$ '- azobisisobutyronitrile, 0.3 equiv) was carried out under CO pressure $(80 \mathrm{~atm})$ in THF $(0.02 \mathrm{M})$ at $80{ }^{\circ} \mathrm{C}$ for $12 \mathrm{~h}$, which gave the desired 4,4-spirocyclic indoline $\gamma$-lactam 2a in $48 \%$ yield (Scheme 4 ). We found that the modest improvement in the yield of $\mathbf{2 a}$ to $53 \%$ was achieved by changing the mediator from $\mathrm{Bu}_{3} \mathrm{SnH}$ to TTMSS [tris(trimethylsilyl)silane].

The tandem spirocyclization with $\mathrm{CO}$ was investigated with several 2-iodoaryl compounds having an allyl azide moiety. Results are summarized in Table 1. The reaction of $N$-(2-(azidomethyl)allyl)- $N$-(2-iodo-5-methoxyphenyl)-4-methylbenzenesulfonamide (1b) with $\mathrm{CO}$ gave the corresponding spiro lactam 2b in 53\% yield (Table 1, entry 2). $N$-(2-(Azidomethyl)allyl)- $N$ (2-iodophenyl)methanesulfonamide (1c) showed a comparable reactivity with $\mathbf{1 a}$ and $\mathbf{1 b}$ (Table 1 , entry 3 ). The reaction of 1-(2-(azidomethyl)allyloxy)-2-iodobenzene (1d) also gave the spiro benzofuran lactam $\mathbf{2 d}$ in $58 \%$ yield (Table 1, entry 4$)$. On<smiles>[Z]C(=C)C(CN)CC(=O)O</smiles><smiles></smiles>

$\mathrm{X}=\mathrm{NR}$ or $\mathrm{O}$ or $\mathrm{S}$

$\mathrm{Y}=\mathrm{H}$, or $\mathrm{OMe}$

$\mathrm{Z}=\mathrm{H}, \mathrm{H}$ or $\mathrm{O}$

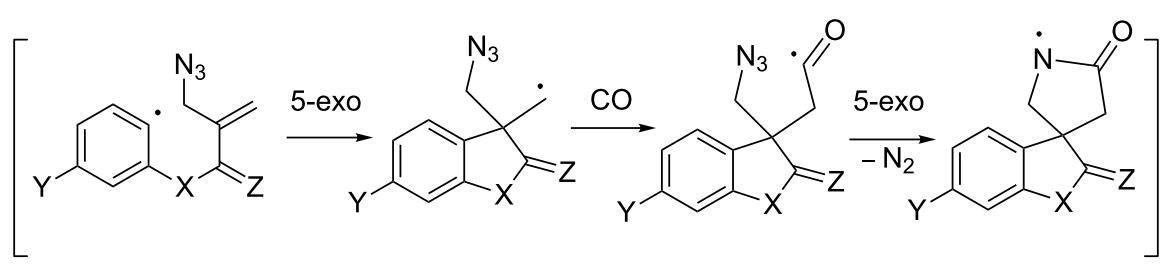



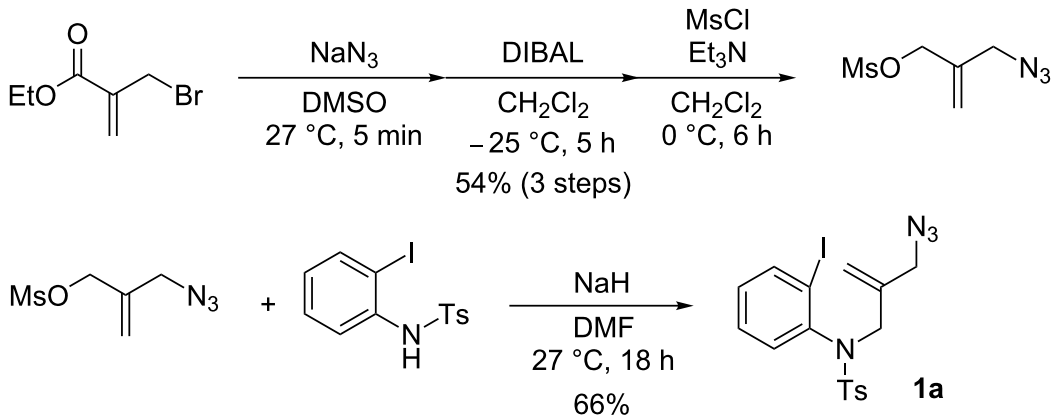

Scheme 3: The synthetic methods of 1a.<smiles>CC1=C(CN)c2ccccc2N([125I])C1</smiles>

1a

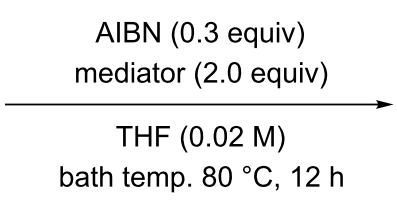

bath temp. $80^{\circ} \mathrm{C}, 12 \mathrm{~h}$<smiles>CN(C)c1ccccc1C12CNC(=O)C1C2</smiles>

$2 \mathbf{a}$

$\mathrm{Bu}_{3} \mathrm{SnH}: 48 \%$

TTMSS: $53 \%$

Scheme 4: The tandem radical spirocyclization reaction of $N$-(2-(azidomethyl)allyl)- $N$-(2-iodophenyl)-4-methylbenzenesulfonamide (1a) with CO.

Table 1: Synthesis of 4,4-spirocyclic $y$-lactams 2 by tandem radical spirocyclization of 1 with CO. ${ }^{a}$

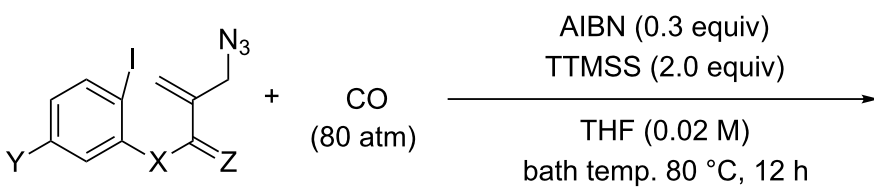

1

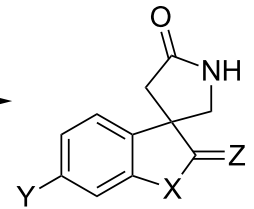

2

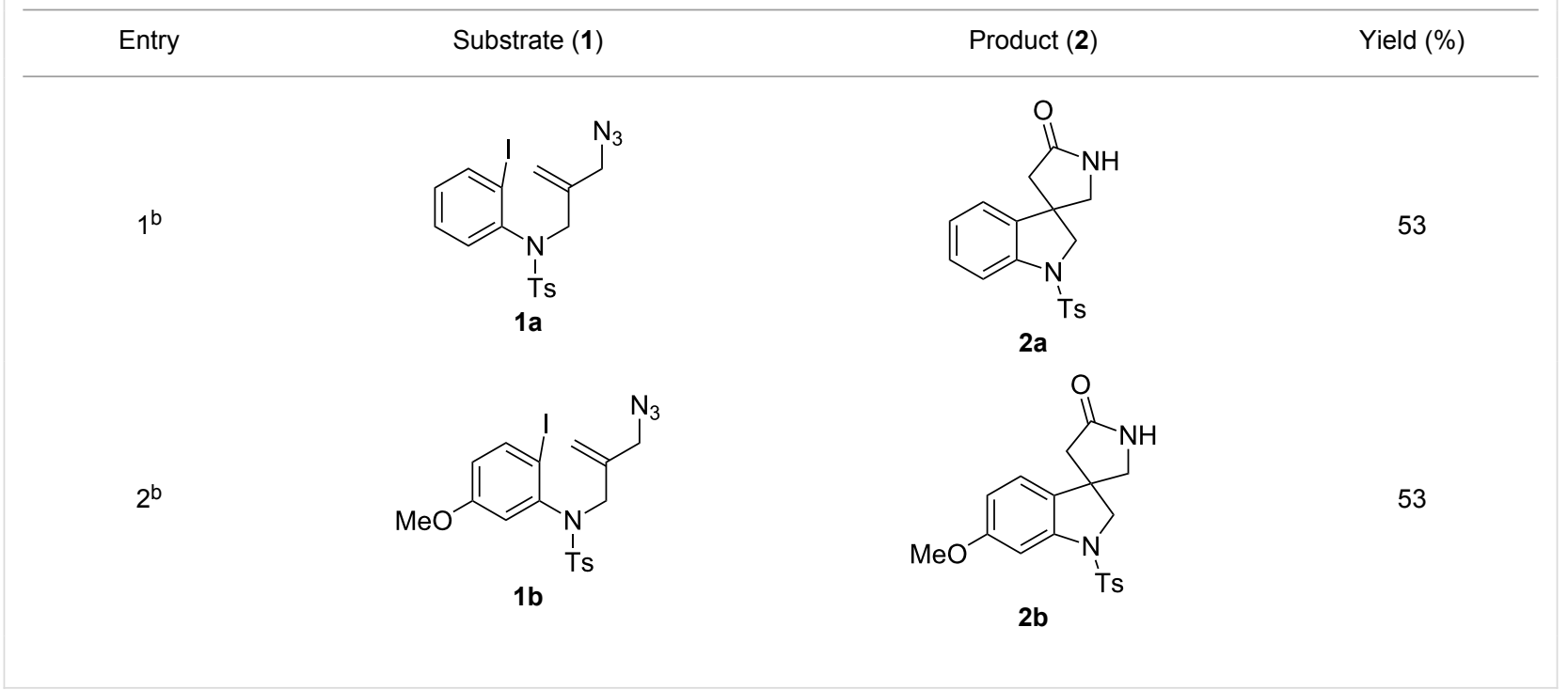


Table 1: Synthesis of 4,4-spirocyclic $\mathrm{y}$-lactams 2 by tandem radical spirocyclization of 1 with CO. ${ }^{\text {a }}$ (continued)

3<smiles>C=C(CN)CN(C)c1ccccc1I</smiles>

4<smiles>C=C(CN)COc1ccccc1I</smiles>

$5^{c}$<smiles>C=C(CN)CSc1ccccc1I</smiles>

6<smiles>C=C(CN)C(=O)N(Cc1ccccc1)c1ccccc1I</smiles>

$1 f$<smiles>C=C(CN)C(=O)Nc1ccccc1I</smiles>

$1 \mathrm{~g}$<smiles>CS(=O)(=O)N1CC2(CNC(=O)C2)c2ccccc21</smiles>

2c<smiles>O=C1CC2(CN1)COc1ccccc12</smiles>

2d<smiles>O=C1CC2(CN1)CSc1ccccc12</smiles>

$2 e$<smiles>O=C1CC2(CN1)C(=O)N(Cc1ccccc1)c1ccccc12</smiles>

$2 f$<smiles>O=C1Nc2ccccc2CC1CC1CCCO1</smiles>

$d r=1: 1$
55

a Reaction conditions: 1 (1.0 equiv), CO (80 atm), AIBN (0.3 equiv), TTMSS (2.0 equiv), THF (0.02 M), bath temperature $80{ }^{\circ} \mathrm{C}, 12 \mathrm{~h} .{ }^{\mathrm{b}}$ Reaction time: $24 \mathrm{~h}$. ${ }^{\mathrm{C}}$ The reaction was carried out at a bath temperature of $110^{\circ} \mathrm{C}$. ${ }^{\mathrm{d} Y}$ Yield of 3.

the other hand, 2-(azidomethyl)allyl(2-iodophenyl)sulfane (1e) gave a low yield of the corresponding spiro thiobenzofuran lactam (19\%, Table 1, entry 5), which may be rationalized by the less effective cyclization due to the longer $\mathrm{C}-\mathrm{S}$ bonds.

We then tried to extend the tandem spirocyclization approach to obtain 4,4-spirocyclic oxindole $\gamma$-lactam and tested two substrates, 2-(azidomethyl)- $N$-benzyl- $N$-(2-iodophenyl)acrylamide (1f) and the nitrogen-unprotected analogue 1g. The reaction of $\mathbf{1 f}$ was smooth to give the desired 4,4-spirocyclic oxindole $\gamma$-lactam $2 \mathrm{f}$ in $62 \%$ yield (Table 1, entry 6 ). On the other hand, the reaction of $\mathbf{1 g}$ gave the cyclized product in only a trace amount, and instead THF-incorporating 6-endo cyclization product 3 was obtained in $60 \%$ yield (Table 1, entry 7) [28].
Based on the known chemistry of radical cyclization and carbonylation reactions, a possible mechanism for the spirocyclization of $\mathbf{1 f}$ with $\mathrm{CO}$ is shown in Scheme 5. The iodoaryl allyl azide $\mathbf{1 f}$ is converted to an aryl radical $\mathbf{A}$ via the iodine atom abstraction by the (TMS) ${ }_{3}$ Si radical. The subsequent 5-exo cyclization of aryl radical $\mathbf{A}$ gives an alkyl radical $\mathbf{B}$, which adds to $\mathrm{CO}$ to give an acyl radical $\mathbf{C}$. Finally, the 5-exo addition of acyl radical $\mathbf{C}$ onto an azide group takes place with the liberation of dinitrogen to give a cyclized amidyl radical $\mathbf{D}$ [29,30], which abstracts hydrogen from TTMSS, affording the 4,4-spirocyclic indoline $\gamma$-lactam $2 \mathrm{f}$ and a (TMS) ${ }_{3} \mathrm{Si}$ radical, thus creating a radical chain.

On the other hand, the unusual formation of THF-incorporating lactam 3 from $\mathbf{1 g}$ may be rationalized by the consecutive 6-endo 


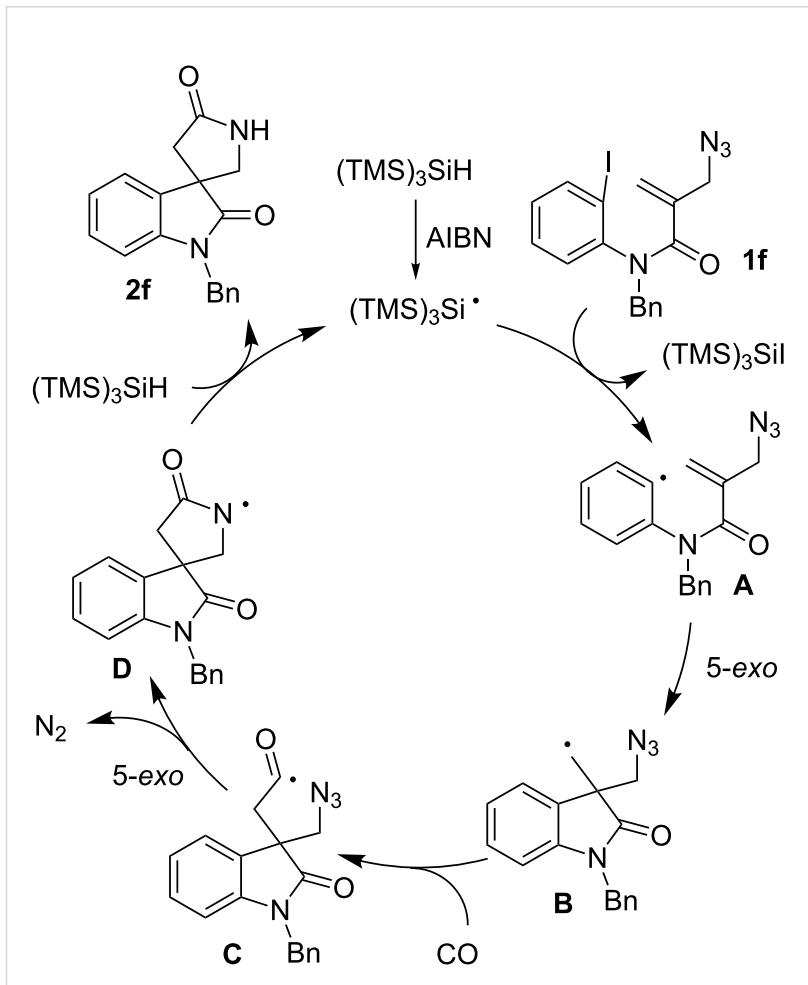

Scheme 5: Proposed mechanism for a construction of 4,4-spirocyclic indoline $\mathrm{y}$-lactam $2 \mathrm{f}$ by the tandem radical cyclization of $1 \mathrm{f}$ with $\mathrm{CO}$.

cyclization of $\mathbf{E}$ and $\beta$-elimination of an azidyl radical from the resulting $\mathbf{F}$, to give 2-methylene lactam $\mathbf{G}$ (Scheme 6). Then, the THF radical is formed via the $\alpha$-hydrogen abstraction by the azidyl radical [31-34], which is attached to $\mathbf{G}$ to give $\alpha$-carbonyl radical $\mathbf{H}$. Finally, $\mathbf{H}$ abstracts hydrogen from TTMSS, affording the THF-incorporating product 3 and the (TMS) $)_{3} \mathrm{Si}$ radical, which participates in the next chain reaction.

\section{Conclusion}

We have examined a TTMSS-mediated 5-exo radical cyclization/carbonylation/spirocyclization sequence to synthesize 4,4spirocyclic rings. By using this protocol, indoline, benzofuran and oxindole $\gamma$-lactams can be conveniently prepared in moderate to good yields. As shown in the contrasting results of acrylic amides $\mathbf{1 f}$ and $\mathbf{1 g}$, to cause the requisite 5-exo cyclization of aryl radicals onto allylic azide in preference to the 6-endo cyclization, the angle compression caused by the substitution on the nitrogen has to be considered carefully. Nevertheless, our method can provide a steady tool for the ring formation of 4,4-spirocyclic $\gamma$-lactams with the incorporation of $\mathrm{CO}$ as a carbonyl group.

\section{Experimental}

Typical procedure for a construction of 4,4-spirocyclic $\gamma$-lactams by tandem radical cyclization with CO: A

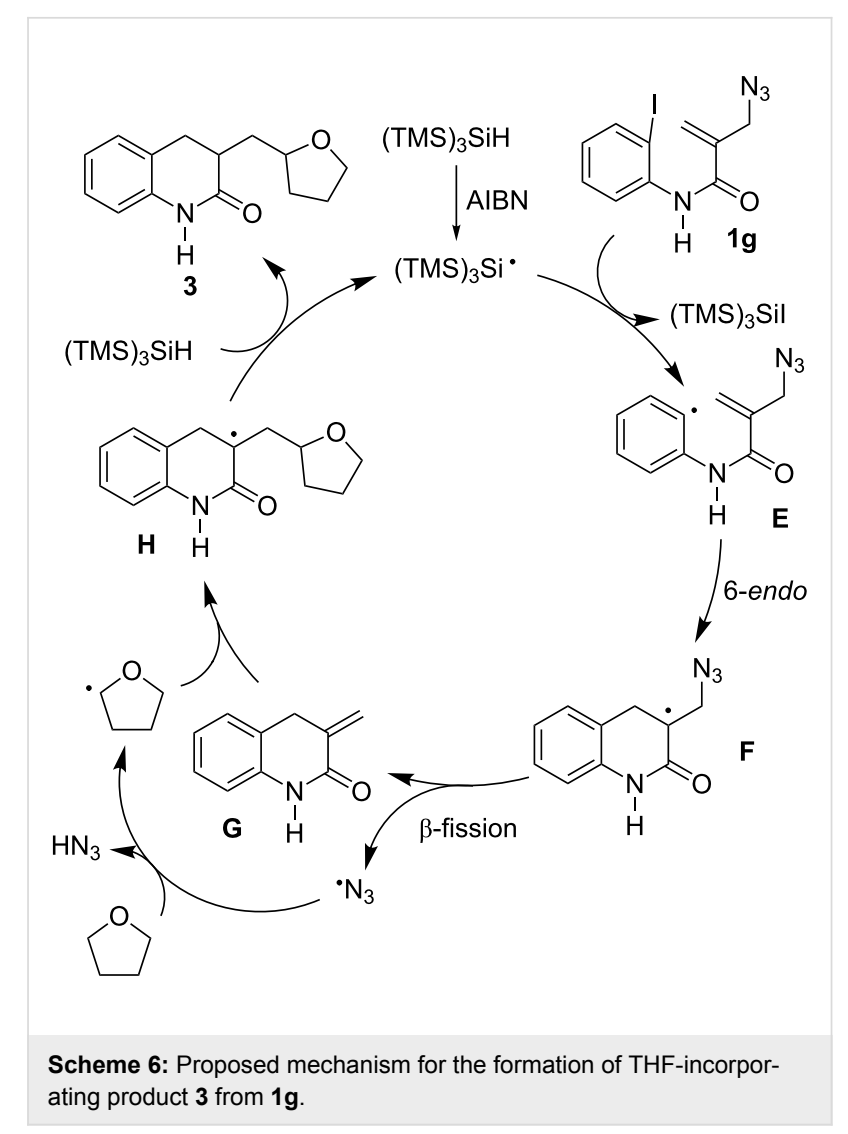

magnetic stirring bar, 2-(azidomethyl)- $N$-benzyl- $N$-(2iodophenyl)acrylamide (1f) $(150.0 \mathrm{mg}, 0.36 \mathrm{mmol})$, AIBN (2,2'-azobisisobutyronitrile, $17.7 \mathrm{mg}, 0.11 \mathrm{mmol}$ ), TTMSS ([tris(trimethylsilyl)silane], $178.3 \mathrm{mg}, 0.72 \mathrm{mmol}$ ) and THF $(17.9 \mathrm{~mL} ; 0.02 \mathrm{M})$ were placed in a $50 \mathrm{~mL}$ stainless steel autoclave. The autoclave was closed, purged three times with $\mathrm{CO}$, pressurized with $80 \mathrm{~atm}$ of $\mathrm{CO}$, and then heated at $80{ }^{\circ} \mathrm{C}$ (bath temperature) for $12 \mathrm{~h}$. Excess $\mathrm{CO}$ was discharged after the reaction. The reaction mixture was concentrated in vacuo. The resulting residue was purified by column chromatography on silica gel (hexane/EtOAc 2:1) to give the desired 4,4-spirocyclic oxindole $\gamma$-lactam product $\mathbf{2 f}$ as a colorless oil in $62 \%$ yield (65.3 mg, $0.22 \mathrm{mmol}) .{ }^{1} \mathrm{H}$ NMR $\left(400 \mathrm{MHz}, \mathrm{CDCl}_{3}\right) \delta$ $7.39-7.16(\mathrm{~m}, 7 \mathrm{H}), 7.07$ (t, $J=7.6 \mathrm{~Hz}, 1 \mathrm{H}), 6.79(\mathrm{~d}, J=7.6 \mathrm{~Hz}$, $1 \mathrm{H}), 5.89(\mathrm{~s}, 1 \mathrm{H}), 4.93(\mathrm{~s}, 2 \mathrm{H}), 3.91(\mathrm{~d}, J=9.2 \mathrm{~Hz}, 1 \mathrm{H}), 3.50$ (d, $J=9.2 \mathrm{~Hz}, 1 \mathrm{H}) 3.02(\mathrm{~d}, J=16.8 \mathrm{~Hz}, 1 \mathrm{H}), 2.51(\mathrm{~d}, J=16.8 \mathrm{~Hz}$, $1 \mathrm{H}) ;{ }^{13} \mathrm{C} \mathrm{NMR}\left(100 \mathrm{MHz}, \mathrm{CDCl}_{3}\right) \delta 177.5,175.4,141.9,135.5$, 133.2, 129.1, 129.0, 128.0, 127.4, 123.6, 122.3, 109.7, 51.1, 49.7, 44.3, 40.4; IR (neat): 3418, 3061, 2927, 1696, 1613, 1488, 1467, 1455, 1380, 1368, $1177 \mathrm{~cm}^{-1}$; HRMS-FAB $(\mathrm{m} / \mathrm{z})$ : $[\mathrm{M}+\mathrm{H}]^{+}$calcd for $\mathrm{C}_{18} \mathrm{H}_{17} \mathrm{~N}_{2} \mathrm{O}_{2}, 293.1290$; found, 293.1299.

\section{Acknowledgements}

This work was supported by a Grant-in-Aid for Scientific Research from the MEXT and JSPS. 


\section{References}

1. Edmondson, S.; Danishefsky, S. J.; Sepp-Lorenzino, L.; Rosen, N. J. Am. Chem. Soc. 1999, 121, 2147-2155. doi:10.1021/ja983788i

2. Cravotto, G.; Giovenzana, G. B.; Pilati, T.; Sisti, M.; Palmisano, G. J. Org. Chem. 2001, 66, 8447-8453. doi:10.1021/jo015854w

3. Marti, C.; Carreira, E. M. Eur. J. Org. Chem. 2003, 2209-2219. doi:10.1002/ejoc.200300050

4. Allous, I.; Comesse, S.; Berkeš, D.; Alkyat, A.; Daïch, A. Tetrahedron Lett. 2009, 50, 4411-4415. doi:10.1016/j.tetlet.2009.02.114

5. Tan, D. Q.; Atherton, A. L.; Smith, A. J.; Soldi, C.; Hurley, K. A.; Fettinger, J. C.; Shaw, J. T. ACS Comb. Sci. 2012, 14, 218-223. doi: $10.1021 / \operatorname{co} 2001873$

6. Beckwith, A. L. J. Chem. Soc. Rev. 1993, 22, 143-151. doi:10.1039/cs9932200143

7. Ishibashi, H.; Sato, T.; Ikeda, M. Synthesis 2002, 695-713. doi:10.1055/s-2002-25759

8. Srikanth, G. S. C.; Castle, S. L. Tetrahedron 2005, 61, 10377-10441. doi:10.1016/j.tet.2005.07.077

9. Fallis, A. G.; Brinza, I. M. Tetrahedron 1997, 53, 17543-17594. doi:10.1016/S0040-4020(97)10060-6

10. Friestad, G. K. Tetrahedron 2001, 57, 5461-5496. doi:10.1016/S0040-4020(01)00384-2

11. Bowman, W. R.; Fletcher, A. J.; Potts, G. B. S. J. Chem. Soc., Perkin Trans. 1 2002, 2747-2762. doi:10.1039/B108582B

12. Minozzi, M.; Nanni, D.; Spagnolo, P. Chem.-Eur. J. 2009, 15, 7830-7840. doi:10.1002/chem.200802710

13. Patro, B.; Murphy, J. A. Org. Lett. 2000, 2, 3599-3601. doi:10.1021/ol006477x

14. Lizos, D. E.; Murphy, J. A. Org. Biomol. Chem. 2003, 1, 117-122. doi:10.1039/b208114h

15. González-López de Turiso, F.; Curran, D. P. Org. Lett. 2005, 7, 151-154. doi:10.1021/ol0477226

16. Zhang, H.; Curran, D. P. J. Am. Chem. Soc. 2011, 133, 10376-10378. doi:10.1021/ja2042854

17. Ryu, I.; Matsu, K.; Minakata, S.; Komatsu, M. J. Am. Chem. Soc. 1998, 120, 5838-5839. doi:10.1021/ja980731n

18. Ryu, I.; Miyazato, H.; Kuriyama, H.; Matsu, K.; Tojino, M.; Fukuyama, T.; Minakata, S.; Komatsu, M. J. Am. Chem. Soc. 2003, 125, 5632-5633. doi:10.1021/ja034896u

19. Tojino, M.; Otsuka, N.; Fukuyama, T.; Matsubara, H.; Schiesser, C. H.; Kuriyama, H.; Miyazato, H.; Minakata, S.; Komatsu, M.; Ryu, I. Org. Biomol. Chem. 2003, 1, 4262-4267. doi:10.1039/b309944j

20. Tojino, M.; Otsuka, N.; Fukuyama, T.; Matsubara, H.; Ryu, I. J. Am. Chem. Soc. 2006, 128, 7712-7713. doi:10.1021/ja0623865

21. Kyne, S. H.; Lin, C. Y.; Ryu, I.; Coote, M. L.; Schiesser, C. H. Chem. Commun. 2010, 46, 6521-6523. doi:10.1039/c0cc01262a

22. Ryu, I.; Fukuyama, T.; Tojino, M.; Uenoyama, Y.; Yonamine, Y.; Terasoma, N.; Matsubara, H. Org. Biomol. Chem. 2011, 9, 3780-3786. doi:10.1039/c1ob05145h

23. Fukuyama, T.; Nakashima, N.; Okada, T.; Ryu, I. J. Am. Chem. Soc. 2013, 135, 1006-1008. doi:10.1021/ja312654q

24. Ryu, I.; Sonoda, N. Angew. Chem., Int. Ed. Engl. 1996, 35, 1050-1066. doi:10.1002/anie.199610501

25. Ryu, I.; Sonoda, N.; Curran, D. P. Chem. Rev. 1996, 96, 177-194. doi:10.1021/cr9400626

26. Ryu, I. Chem. Soc. Rev. 2001, 30, 16-25. doi:10.1039/a904591k

27. Chatgilialogu, C.; Crich, D.; Komatsu, M.; Ryu, I. Chem. Rev. 1999, 99, 1991-2070. doi:10.1021/cr9601425
28. Jones, K.; Wilkinson, J. J. Chem. Soc., Chem. Commun. 1992, 1767-1769. doi:10.1039/C39920001767 Similar 6-endo cyclization was reported previously.

29. Kim, S.; Joe, G. H.; Do, J. Y. J. Am. Chem. Soc. 1994, 116, 5521-5522. doi:10.1021/ja00091a087

30. Benati, L.; Leardini, R.; Minozzi, M.; Nanni, D.; Spagnolo, P.; Strazzari, S.; Zanardi, G. Org. Lett. 2002, 4, 3079-3081. doi:10.1021/ol026366t

31. Viuf, C.; Bols, M. Angew. Chem., Int. Ed. 2001, 40, 623-625. doi:10.1002/1521-3773(20010202)40:3<623::AID-ANIE623>3.0.CO;2$\mathrm{G}$

32. Marinescu, L. G.; Pedersen, C. M.; Bols, M. Tetrahedron 2005, 61, 123-127. doi:10.1016/j.tet.2004.10.040

33. Pedersen, C. M.; Marinescu, L. G.; Bols, M. Org. Biomol. Chem. 2005, 3, 816-822. doi:10.1039/b500037h

34. Klima, R. F.; Jadhav, A. V.; Singh, P. N. D.; Chang, M.; Vanos, C.; Sankaranarayanan, J.; Vu, M.; Ibrahim, N.; Ross, E.; McCloskey, S.; Murthy, R. S.; Krause, J. A.; Ault, B. S.; Gudmundsdóttir, A. D. J. Org. Chem. 2007, 72, 6372-6381. doi:10.1021/jo070558q

\section{License and Terms}

This is an Open Access article under the terms of the Creative Commons Attribution License (http://creativecommons.org/licenses/by/2.0), which permits unrestricted use, distribution, and reproduction in any medium, provided the original work is properly cited.

The license is subject to the Beilstein Journal of Organic Chemistry terms and conditions: (http://www.beilstein-journals.org/bjoc)

The definitive version of this article is the electronic one which can be found at: doi:10.3762/bjoc.9.151 